\title{
PROOF OF BÖTTCHER AND WENZEL'S CONJECTURE
}

\author{
SEAK-WENG VONG AND XIAO-QING JIN
}

Abstract. In 2005, Böttcher and Wenzel raised a conjecture that if $X$ and $Y$ are any two real $n$-by- $n$ matrices, then $\|X Y-Y X\|_{F}^{2} \leqslant 2\|X\|_{F}^{2}\|Y\|_{F}^{2}$ where $\|\cdot\|_{F}$ denotes the Frobenius norm. They proved this for the case of 2 -by- 2 matrices. Later, László proved the conjecture for the case of 3 -by- 3 matrices. In this paper, we prove the conjecture for general $n$-by- $n$ matrices. identity.

Mathematics subject classification (2000): 15A52, 15A45, 60H25, 65F35.

Key words and phrases: Commutator of two matrices, the Cauchy-Schwarz inequality, the Lagrange

\section{REFERENCES}

[1] A. BötTChER AND D. WenZEL, How big can the commutator of two matrices be and how big is it typically? Linear Algebra Appl., Vol. 403 (2005), pp. 216-228.

[2] R. Horn and C. Johnson, Matrix Analysis, Cambridge University Press, Cambridge, 1985.

[3] L. LÁszLó, Proof of Böttcher and Wenzel's conjecture on commutator norms for 3-by-3 matrices, Linear Algebra Appl., Vol. 422 (2007), pp. 659-663. 